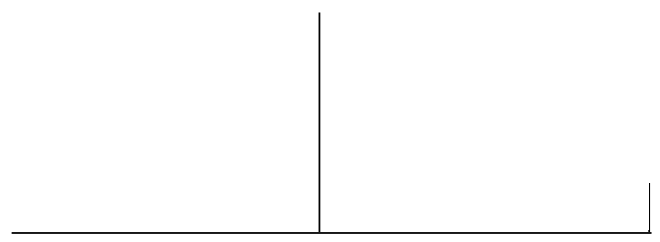

Rev. Latinoam. Psicopat. Fund., São Paulo, 16(3), 453-467, set. 2013

\title{
Sobre ciúmes e erotomania: reflexões acerca de um caso clínico
}

Fernanda Costa Rios*

Este artigo aborda os temas do ciúmes e da erotomania a partir de um caso clínico. O ciúme foi retomado partindo de sua manifestação primordial na gênese da constituição do psiquismo em direção a seus desdobramentos patológicos. A erotomania foi abordada a partir do referencial psiquiátrico clássico e não daquele encontrado nos atuais manuais diagnósticos. A articulação dos dois temas, embora não tenha visado qualquer intenção diagnóstica, apontou para uma posição subjetiva regressiva, de estruturação narcísica, delirante e com frágil conjugação do corpo.

Palavras-chave: Caso clínico, ciúmes, erotomania, delírio

*Faculdade de Saúde Pública da Universidade de São Paulo - USP (São Paulo, SP, Brasil) 


\section{Narrativa clínica}

Dado tinha pouco menos de vinte anos quando chegou ao consultório se queixando de "ciúme incontrolável". Se por um lado exigia do namorado tudo saber sobre o que se passara na sua ausência, por outro, flertava, trocava telefones e ocupava-se em imaginar possíveis encontros. Em casa, com os pais, falava só o necessário e, com as irmãs, não se relacionava.

Nas sessões narrava, de forma sistemática, suas muitas desconfianças e discussões com o namorado. Sua fala era bastante preenchida e praticamente sem pausas, queria dar conta de tudo que havia ocorrido sem que nada se perdesse. Após intervenções não era incomum que continuasse falando de onde havia sido interrompido e, mesmo após o anúncio do fim da sessão, às vezes já com a porta aberta, ele seguia falando. Era muito cuidadoso com a aparência e gostava de perguntar se estava bonito.

Ao final das inúmeras discussões com o namorado tinha vontade de acabar tudo, sentia que depois de terem ido longe com as palavras algo se perdeu e, se algo se perdeu, ele não queria mais. O namoro chegara ao fim, mas não sem que o contato entre eles se estendesse por meses inclusive adentrando seus próximos relacionamentos. Nesta época tentou retomar antigas amizades, "Fiquei me sentindo meio de fora, com ciúmes dos amigos e brincadeiras novas", verbalizou alguns desejos, "Quero ser menos inseguro, amadurecer para me relacionar melhor", e fez indagações do tipo "Como fazemos para sermos mais completos?". Foi também nesta época que uma estranha desconfiança passou a lhe 
preocupar. Dado passara a acreditar que uma de suas colegas, pela maneira com que verbalizara a palavra "fechou", antes de lhe passar o cigarro, tinha conhecimentos sobre a magia de fazer mal aos outros e, mesmo evitando encontrá-la, culpava-a por sentir determinadas dores na perna esquerda e na cabeça.

A estranha desconfiança foi lentamente perdendo força para a tenaz e familiar falta de confiança em seu novo namorado, também chamado Dado: "Tudo está se repetindo da mesma maneira". Ele imaginava Dado em ato sexual com os exnamorados e, muitas vezes, se demorando em cada detalhe, acabava por chorar. Exatamente como antes, cobrava e exigia constantes provas de fidelidade até que, em determinado momento, passou a acreditar que o pai de Dado ao verbalizar "é dele", em uma ocasião na qual fritava e distribuía pastéis, estaria também lhe fazendo mal.

Ao final de um ano Dado e Dado não estavam mais juntos embora ainda se mantivessem informados da vida um do outro. Ele temia que mesmo a distância, a colega, o pai de Dado e Dado, pudessem estar lhe fazendo mal. Se incomodava com os olhares das pessoas na rua e às vezes passava dias preocupado em perder algum membro ou o movimento das pernas.

Afinal, como entender a experiência do ciúme? E o medo de perder um membro? Será que existiria algo em comum entre o medo de ter um membro subtraído e o medo de ser traído? Por que, mesmo ciumento, Dado flertava com outros quando saía à rua? Será que se poderia pensar em uma certa mania de ser amado? Dado dizia o tempo todo que era perseguido, que lhe faziam mal; no entanto, o que é possível perceber em seu discurso é que ele perseguia o outro e impedia a relação. Por que isso ocorria?

\section{Dos ciúmes}

O ciúme é um sentimento que certamente, em menor ou maior intensidade, todos já tiveram a oportunidade de experienciar. Guarda em si o medo da perda e atualiza angústias arcaicas que fizeram parte da constituição do psiquismo de todo indivíduo.

\section{Do ciúme primordial}

Dentre as primeiras inscrições realizadas no psiquismo do bebê está a marca da satisfação proporcionada pelo peito na hora da fome. É sabido que este re- 
gistro primário de prazer, rememorado após cada mamada, proporciona enorme bem-estar e favorece no bebê o surgimento da sensação de completude, de que ele e o peito, juntamente com sua extensão, a mãe, juntamente com sua extensão, formam uma totalidade. Esta ilusão essencial neste primeiro momento guarda em si a garantia de que os cuidados necessários para que o bebê humano, vulnerável e extremamente dependente, realize seu momento inaugural no que se refere ao desenvolvimento do núcleo de sua subjetividade.

Com a aproximação do momento do desmame, a ilusão construída e sustentada - já com dificuldades devido ao peito faltar ou se demorar em momentos em que o bebê o deseja sem delongas - irá ceder lugar ao mal-estar vivenciado pela separação desta totalidade, nomeada por Freud das Ding ou "a coisa". O desmame é reconhecido como uma crise vital no psiquismo em formação, ele funda os sentimentos mais arcaicos e mais estáveis que unem o indivíduo à família, deixando traço permanente da relação biológica que ele interrompe (Lacan, 1984). É uma separação similar a do nascimento e pertence à série de rupturas importantes a serem vividas pela dupla mãe-criança. O desmame está ligado ao objeto responsável pela primeira inscrição de prazer e vivência de satisfação. A experiência da separação mãe-criança permitirá a ocorrência de eventos decisivos referentes a fundação do eu e a constituição do sujeito que se encontram diretamente relacionados com a vivência primordial do ciúme. Irá se esboçar no sujeito primitivo o reconhecimento de que além dele existem outros, fato que é vivido como uma intrusão, como se o terceiro que surge estivesse a mais e, existindo um a mais, a ameaça de separação e de perda do primeiro objeto de amor estaria formalizada. Concomitante ao declínio do desmame e a vivência da intrusão, a criança está às voltas com a identificação mental e o momento inaugural de reconhecimento da própria imagem. Ela irá reconhecer o reflexo de si em outro lugar que não nos olhos da mãe, se apercebendo de que aquela imagem refletida no espelho, alvo dos afetos e do olhar apaixonado da mãe, é a imagem totalizadora do seu ser. Pela primeira vez e através do recorte feito pelo olhar materno, a criança, seduzida pela própria imagem, terá a vivência de ser discriminada do todo, de ser uma unidade separada, com seus próprios contornos e limites. Momento de muitas formulações, o estádio do espelho ilustra o caráter de relação de reciprocidade entre sujeito e objeto, relação em espelho (Lacan, 1956-1957). Fala-se em identificação mental, já que o eu se constitui ao mesmo tempo em que o outro, no drama do ciúme (Lacan, 1984), que tem sua origem no próprio momento da identificação com os irmãos. Não existe outro como objeto enquanto a criança não tiver passado pelo estádio do espelho e se destacado como tal. É só após este momento que ela irá conhecer sentimentos de pertencimento ou de propriedade, antes disso ela é o mundo, assim como a outra criança também o é (Lachaud, 2001). À 
criança, que deixa de ser tudo para ser uma unidade e que vive o drama do ciúme ao se identificar com o outro, podendo se colocar no seu lugar, estão sendo introduzidos os primeiros registros da castração. Ao turbilhão de afetos vividos em decorrência das tantas mudanças, a criança geralmente reage com raiva e agressividade, além de tentar permanecer única para a mãe, resistindo à separação e a verdade sobre ser não-toda, como the foi assegurado em um primeiro momento.

Embora a entrada do terceiro seja reconhecida como desagradável, sua exclusão deixaria o sujeito alienado. $\mathrm{O}$ quanto antes a triangulação começar a intervir, melhor será para que os conflitos subjetivos possam se expressar de maneira, que se poderia dizer, mais saudável. Há uma participação importante do ciúme na experiência fundadora da instalação do sujeito (Lachaud, 2001).

\section{Do ciúme patológico}

Importante tanto na inauguração do sujeito como na origem de sua sociabilidade, o ciúme representa em sua essência uma identificação mental (Lacan, 1984). É pela identificação que o sujeito em constituição é apresentado ao mundo e que se dá o rompimento da relação dual imaginária com a mãe (Lachaud, 2001) que, enquanto mantida, sustenta uma imagem totalizadora de algo completo e acabado que nada prescinde nem nunca está em falta. Essa imagem nostálgica da completude uma vez vivida será, no decorrer da vida, para sempre buscada e incessantemente não encontrada. De acordo com Freud (1920-1922), a identificação é a mais remota expressão de um laço emocional com outra pessoa. Ela é desde o início ambivalente podendo se tornar ternura ou, com muita facilidade, o desejo de eliminar o outro. Por se derivar da primeira fase da organização da libido - a fase oral - a identificação se dá pela primeira vez em um momento no qual o objeto que a criança preza e anseia é assimilado pela ingestão e, desta maneira, aniquilado como tal. A violência do aniquilamento junto a violência da separação/castração se efetuam sobre um fundo de ódio pela mãe que fez a criança não-toda e, pelo terceiro, intruso e operador da separação (Lachaud, 2001). O desejo de que o outro desapareça está na mesma medida em que este representa e sustenta o desejo do sujeito, pois não há desejo sem inscrição da falta (Brasil, 2009). Enquanto o ciúme é a reivindicação do todo, a questão do desejo se apresenta como algo que se recusa ao todo. $\mathrm{O}$ ciumento, em sua demanda de ser o único e insubstituível, reivindica o todo, numa posição imaginária de possível totalização (Lachaud, 2001). Se o irmãozinho é o primeiro intruso, logo o pai no caso da mãe lhe garantir um lugar - vai se tornar também um intruso entre a 
mãe e a criança e assim, sucessivamente, em intensidades variadas, em suas futuras relações. O intruso que se deseja eliminar ocupa o lugar do rival, portador imaginarizado daquilo que lhe falta. Ao mesmo tempo em que há uma identificação com o semelhante, a existência deste outro atualiza a verdade de sua incompletude. O ciumento acredita não possuir todo o objeto de seu amor ou todo o amor do objeto amado, não porque isto lhe seja impossível, mas porque alguém o rouba (Brasil, 2009). O rival é este outro no qual o sujeito projeta seu ser de falta, é um semelhante, ele mesmo, igual e real, um ser faltante que procura preencher sua falta com o objeto que "é do sujeito" (Quinet, 2009, p. 135). O ciumento vive sob a ameaça permanente de uma despossessão (Lachaud, 2001), numa com-fusão entre o semelhante, o outro e ele mesmo. Pensa possuir o objeto que preencherá sua falta, não fosse o enorme medo de perdê-lo para o outro. O ódio e o desejo de destruição revelam, pela relação especular, sua busca para que o outro não usufrua de sua própria dimensão desejante, pois assim, em momento algum, apareceria uma separação. Independentemente de ocorrer em momentos primitivos do desenvolvimento ou em fase adulta, o ciúme estará sempre remetido a um desejo furioso de retorno à mãe (Lachaud, 2001), a uma nostalgia da matriz (Levy, 2009), ou pode-se dizer, a um desejo de retorno ao amor materno, amor arcaico cuja condição fundamental é a completa harmonia de interesses (Balint, 1939).

$\mathrm{O}$ ciúme flerta com a totalidade e corresponde à tentativa de desconhecer a falta fundamental, acusando o outro de roubo do impossível: a posse total do objeto de amor. $\mathrm{O}$ que os ciumentos não percebem é que o verdadeiro rival que eles combatem é o desejo, ou melhor, é a autonomia do desejo o que eles tentam controlar. O ciumento não suporta a satisfação do outro, tampouco seu gozo. Ele procura e quer tudo, tenta privar o outro daquilo que ele goza. Em outras palavras, o ciumento tende para o narcisismo total e absoluto, sem falha (Lachaud, 2001).

O ciumento afirma que a fala mente, que o enunciado abriga a mentira, para ele não existe verdade acessível, mas ele quer saber, nem que seja contra a verdade. Há no ciúme patológico uma verificação que nenhuma prova jamais poderá satisfazer. Encontrar o que o ciumento busca não o acalmaria (Lachaud, 2001).

\section{De volta ao caso}

Dado, em seus relacionamentos, reivindica constantemente tudo ter, tudo querer saber, tudo dizer, como se lhe fosse possível nunca estar em falta. Sua fala 
preenchida e quase sem pausas fazia das sessões um bloco maciço e compacto. Fosse no vazio entre uma palavra e outra, fosse entre uma história e outra, a falta era incessantemente suprimida. Sem escutar nem parar de falar, precisava dar conta de tudo, desde onde parou no último encontro, até o presente, chegando a ignorar o anúncio do fim da sessão. Presente em todos seus relacionamentos, o movimento de recusa à separação, evidencia um tipo de fusão idealizada onde a manifestação do desejo do outro era, em seu caráter ameaçador, negada ou revidada. Ora no término de cada sessão, ora com seus familiares e namorados, sempre que se sentia ameaçado de despossessão do que acreditava ser seu, agia com violência. Não foi senão de forma brusca que conseguiu se separar dos pais, lá atrás no início de sua adolescência. E não sem que, dali em diante, lhes dirigisse ódio por meio de brigas e discussões por o terem feito não-todo. Com suas irmãs não se relacionava e é possível que seja, em parte, por serem mulheres e carregarem no corpo o próprio registro do não ter e, em parte, por não lhe ser possível manejar os ciúmes.

Em seu último relacionamento amoroso, Dado elegeu outro Dado como parceiro, radicalizando o que se denomina relação especular. Em sua com-fusão, reciprocamente ocupou o lugar do sujeito e do objeto que lhe completaria.

Interessante levar em conta os significantes "fechou" e "é dele", presentes na ideia delirante de lhe estarem fazendo mal, bem como a situação fantasmática de seus agentes. Na primeira situação uma menina, novamente, ao menos no real do corpo, detentora do não ter, em posse do mistério do gozo feminino em seu aspecto além da matéria e sem bordas, ao verbalizar "fechou", foi a agente no descobrimento/des-velamento da falta-a-ser de Dado. Na segunda situação, o pai de Dado, por excelência, representante da lei e de importante papel na realização do corte/separação da coisa - das Ding freudiano - ao dizer "é dele" provocou toda uma atualização do conflito edípico e, consequentemente, daquilo que se inscreveu de maneira claudicante em Dado. Na ausência das associações do paciente, o que seria sobremaneira mais adequado, realizou-se breve pesquisa sobre o conteúdo do que poderia estar presente nessas verbalizações. Para o verbo fechar foram encontradas as seguintes definições: tapar uma abertura, fazer cessar o estado de aberto, unir as bordas de uma abertura, unir-se e condensar-se entre outras. No caso de "é dele" tem-se o verbo ser conjugado em concordância com o pronome possessivo dele. Os pronomes possessivos são usados para indicar a posse de algo (coisa possuída) por alguém (possuidor). Embora essas produções de sentido não tenham a importância das associações produzidas por Dado, elas oferecem, de alguma maneira, sintonia com o conflito presente em seus sintomas: a ameaça permanente de despossessão da coisa (das Ding), bem como sua tendência para o narcisismo total e absoluto. 


\section{Da erotomania}

A definição de erotomania mais comumente encontrada na atualidade é a utilizada no Manual Diagnóstico e Estatístico de Doenças Mentais, o DSM-IV. É descrita como uma forma de delírio, denominado Transtorno Delirante do tipo Erotomaníaco, cujo tema central gira em torno de ser amado por outra pessoa, geralmente com uma posição social superior, como, por exemplo, no trabalho ou alguma personalidade pública. Tem a característica de ser um tipo de amor mais romântico do que sexual. A erotomania também é conhecida por Síndrome de Clérambault quando compreendida como algo mais amplo que um delírio. A síndrome leva o nome do psiquiatra francês Gaëtan Gatian de Clérambault (18721934) que publicou sob o tema de Psicoses passionais, em 1921, uma ampla discussão sobre as manifestações da erotomania, dos delírios de ciúmes, de interpretação e de reivindicação. Embora atualmente a definição utilizada no DSMIV seja mais específica e, consequentemente mais limitada, de acordo com o próprio Clérambault, a complexidade do que está contido no interior do termo erotomania parece não poder ser dada por uma definição unívoca (Clérambault, 1921). Para ele, o bloco da erotomania permanece mesclado e foi da riqueza e heterogeneidade deste bloco, em sua dimensão histórica, para além de seus conceitos e comportamentos-alvo (Berrios, 1994) delimitados na atualidade, que surgiu a aproximação desse tema com o caso em questão.

\section{Da síndrome de Clérambault: a erotomania}

A erotomania é uma afecção mental na qual as ideias amorosas são fixas e dominantes (Esquirol, 1815). Elas podem estar remetidas tanto a um ser real como a um objeto imaginário (du Saulle, 1884). Os erotômanos são noite e dia perseguidos pelas mesmas ideias e pelos mesmos afetos, os quais são ainda mais desordenados por estarem concentrados e exasperados pela contrariedade. São eles o temor, a esperança, o ciúme, a alegria e o furor, entre outros (Moreau, 1887). A patogenia da erotomania, bem como dos delírios de reivindicação e de ciúme, se caracterizam por mecanismos ideativos nos quais, no delírio, é colocada em jogo, logo de saída, a vontade do paciente e também o fato dele avançar em direção a um objetivo preciso com exigência consciente e completa desde o início. O paciente não delira senão no domínio de seu desejo, e a feição veemente é comum aos três casos (Clérambault, 1921). De acordo com Clérambault, pode-se afirmar que, do ponto de vista da composição, os delírios erotomaníacos comportam alucinações tanto auditivas quanto genesíacas e ideias de perseguição 
sistemáticas ou não. Do ponto de vista da complexidade pode-se dizer que são capazes de uma extensão irradiada e indefinida, ou então que são inextensíveis, ou ainda, capazes de uma extensão polarizada. Do ponto de vista da evolução é possível que o tema inicial continue ou se modifique, que troque de objetos, ou ainda, que admita objetos múltiplos. Por vezes, o delírio pode cessar durante períodos bastante longos, renascendo, no entanto, pois sua fonte está, em grande parte, no caráter.

$\mathrm{Na}$ erotomania, a contribuição passional oferecida ao objeto de seu amor tem a característica de ser inversamente proporcional a importância da contribuição imaginativa, ou seja, ama-se muito mais em pensamentos, fantasias e demandas, do que na oferta, conquista e manutenção do amor. De alguma forma, esses pacientes se esquecem de si mesmos, ficam inquietos, sonhadores e coléricos. Imaginam que são olhados e que são amados (du Saulle, 1884). As interpretações aparecem mesmo longe do ser amado (Serieux, 1909). Possuem geralmente loquacidade inesgotável, sempre falando sobre seu amor (Moreau, 1887). É frequente o erotômano se tornar o verdadeiro perseguidor em relação ao objeto amado que não lhe retribui na mesma moeda e, sob o pretexto de ser perseguido, se tornar o pior dos perseguidores (Cullere, 1888).

Esses pacientes costumam ter atitude sonhadora, sem energia e com pessimismo universal, comumente acompanhado de hipocondria (Krafft-Ebbing, 1897). No que se refere ao objeto do erotomaníaco, apesar dele ser colocado no lugar de imprescindível, e de amor absoluto, sua substituição por um novo objeto merece ser considerada (Clérambault, 1921). Não sendo raro que este tipo de ideia fixa volte a aparecer de forma inesperada em relacionamentos futuros de maneira bastante parecida. Para Clérambault (1921) as síndromes passionais podem se apresentar tanto em sua forma autônoma e pura quanto associada a outros delírios (intelectuais ou alucinatórios). Desta maneira, podem ser prodrômicas ou sobrepostas, geralmente perdendo sua intensidade à medida que perdem sua pureza. Nelas, a personalidade do indivíduo como um todo, é ameaçada.

\section{De volta ao Dado}

Em sua loquacidade inesgotável e difícil de ser interrompida, Dado era perseguido (ou seria o perseguidor?) por ideias amorosas fixas e dominantes, pelas quais se comportava de maneira a flertar, nas ruas por onde passava, no metrô, ou descendo do ônibus e a se perguntar: "Será que é este o cara?". No caso da menor possibilidade de acontecer um encontro amoroso passava bastante tempo imaginando como teria sido todo o resto. Imaginar era algo de que se ocupava 
bastante e não era incomum que privilegiasse ficar em casa fantasiando a ir ao colégio, ao trabalho ou as reuniões de amigos. Ele chegou a perder dois empregos e o último ano escolar por faltas.

A forma com que perguntava na saída do consultório se estava bonito, não deixava muitas alternativas quanto a possíveis respostas, a não ser a resposta esperada. Esse tipo de constrangimento imposto ao outro encontra relação com o que Clérambault observou sobre, veementemente, o paciente avançar, com exigência consciente, de sua vontade, em direção a um objetivo preciso. Daí os erotômanos serem os verdadeiros e piores perseguidores. Dado se produzia para sair de casa, se vestia de maneira a cuidar de cada detalhe buscando atrair para si os olhares e o interesse dos outros. Algumas vezes trocava telefones, sentindo-se olhado e amado e, em outras, incomodava-se com os olhares e dizia: "Acho que eu tenho mania de perseguição, tudo que acontece a minha volta penso que é comigo". Suas demandas, de ser amado, de ser o único e de ter toda a atenção e dedicação do outro, surgiam muito mais em um contexto de reivindicação do que em uma via de mão dupla, também cultivada por ele. Dado amaria muito mais ser amado do que viver a sua história de amor com alguém.

\section{Considerações finais}

O ciúme tem suas raízes em um momento onde as noções de $e u$ e de outro estão se esboçando pela primeira vez. No diferenciar-se entre eu e tudo, bem como, entre eu e outro, estão implicadas angústias arcaicas convocadas no tom primitivo das cenas de ciúmes. Diferenciar-se do tudo implica em angústias de separação, de perda e de despedaçamento que precedem a vivência do corpo como unidade. As preocupações hipocondríacas de Dado, as dores do lado esquerdo do corpo e o temor de perder um membro estariam remetidos a esta conjugação de corpo ainda frágil e ameaçada.

A captura do $e u$ pela imagem virtual do espelho, em sua importante função unificadora, se faz também alienante e ilusória. Ela traz à cena o aspecto de correspondência mútua de lugares, de relação em espelho e, desta maneira, dá início ao jogo de identificações que será incansavelmente repetido por todos nós. Existiria uma linha tênue entre os jogos identificatórios ditos normais e os reconhecidamente patológicos. Dado viveria patologicamente vacilante dentro deste jogo de reciprocidade topológica.

No decorrer da análise, ele formalizou dilemas que, como numa fotografia, apontava a posição regressiva a qual se encontrava. Trouxe o desejo de "amadurecer para se relacionar melhor" concomitantemente ao questionamento sobre " $o$ 
que fazer para sermos mais completos?". Dado oscilaria entre uma posição desejante e uma posição de totalização, narcísica e imaginária. No movimento pendular de investimento de amor, ora nas relações com o mundo, ora em si mesmo (Freud, 1914), nele tenderia a prevalecer o movimento de investimento libidinal no eu. Diante de tal estruturação narcísica, restaria de fato, aos outros, em suas relações com Dado, poucos lugares possíveis. Podiam servir-lhe para realçar seu próprio valor ou, de maneira oposta, configurarem-se como ameaça ou perseguidores. Ambos, lugares definidos e bem representados em seus relacionamentos.

\section{Referências}

Balint, A. (2009). Amor pela mãe e amor materno. Revista da Associação Psicanalítica de Porto Alegre (Ciúmes), Porto Alegre, n. 37, 112-130. (Trabalho original publicado em 1939).

Berlinck, M. T. \& Berrios, G. E. (Orgs.) (2009). Erotomania. São Paulo: Escuta. (Biblioteca de Psicopatologia Fundamental).

Berrios, G. E. (2009). Erotomania: uma história conceitual. In M. T. Berlinck \& G. E. Berrios (Orgs.). Erotomania (pp. 21-50). São Paulo: Escuta. (Biblioteca de Psicopatologia Fundamental).

Brasil, A. (2009). Psicopatologia da vida amorosa. Revista da Associação Psicanalítica de Porto Alegre (Ciúmes), Porto Alegre, n. 37, 9-21.

Cullere, A. (2009). Perseguidores perseguidos. In M. T. Berlinck \& G. E. Berrios (Orgs.). Erotomania (pp. 181-196). São Paulo: Escuta. (Biblioteca de Psicopatologia Fundamental). (Trabalho original publicado em 1888).

Cullere, A. (2009). Erotomaníacos. In M. T. Berlinck \& G. E. Berrios (Orgs.). Erotomania (pp. 197-202). São Paulo: Escuta. (Biblioteca de Psicopatologia Fundamental). (Trabalho original publicado em 1888).

De Clérambault, G. G. (2009). Os delírios passionais, erotomania, reivindicação, ciúme. In M. T. Berlinck \& G. E. Berrios (Orgs.). Erotomania (pp. 285-298). São Paulo: Escuta. (Biblioteca de Psicopatologia Fundamental). (Trabalho original publicado em 1921).

De Clérambault, G. G. (2009). Erotomania pura. Erotomania associada. In M. T. Berlinck \& G. E. Berrios (Orgs.). Erotomania (pp. 299-330). São Paulo: Escuta. (Biblioteca de Psicopatologia Fundamental). (Trabalho original publicado em 1921).

DSM-IV (1995). Manual Diagnóstico e Estatístico de Transtornos mentais. Porto Alegre: Artes Médicas.

Du Saulle, H. L. (2009). A erotomania. In M. T. Berlinck \& G. E. Berrios (Orgs.). Erotomania (pp. 119-132). São Paulo: Escuta. (Biblioteca de Psicopatologia Fundamental). (Trabalho original publicado em 1884). 
Du Saulle, H. L. (2009). A loucura do amor. In M. T. Berlinck \& G. E. Berrios, Erotomania (pp. 133-136). São Paulo: Escuta. (Biblioteca de Psicopatologia Fundamental). (Trabalho original publicado em 1884).

Esquirol, J.-É. (2009). Erotomania. In M. T. Berlinck \& G. E. Berrios, Erotomania (pp. 109-118). São Paulo: Escuta. (Biblioteca de Psicopatologia Fundamental). (Trabalho original publicado em 1815).

Freud, S. (1996). Notas psicanalíticas sobre um relato autobiográfico de um caso de paranoia (dementia paranoides). In Edição Standard Brasileira das Obras Psicológicas Completas de Sigmund Freud (V. 10). Rio de Janeiro: Imago. (Trabalho original publicado em 1911/1913).

Freud, S. (1996). Introdução ao narcisismo. In Edição Standard Brasileira das Obras Psicológicas Completas de Sigmund Freud (V. 12). Rio de Janeiro: Imago. (Trabalho original publicado em 1914/1916).

Freud, S. (1996). A identificação. In Edição Standard Brasileira das Obras Psicológicas Completas de Sigmund Freud (V. 13). Rio de Janeiro: Imago. (Trabalho original publicado em 1920/1922).

Freud, S. (1996). Alguns mecanismos neuróticos no ciúme, na paranoia e no homossexualismo. In Edição Standard Brasileira das Obras Psicológicas Completas de Sigmund Freud (V. 13). Rio de Janeiro: Imago. (Trabalho original publicado em 1920/1922).

Krafft-Ebing, R. von (2009). Paranoia erótica (Erotomania). In M. T. Berlinck \& G. E. Berrios, Erotomania (pp. 211-220). São Paulo: Escuta. (Biblioteca de Psicopatologia Fundamental). (Trabalho original publicado em 1897).

Krafft-Ebing, R. von (2009). Paranoia sexualis com seus tipos clínicos. In M. T. Berlinck \& G. E. Berrios, Erotomania (pp. 221-228). São Paulo: Escuta. (Biblioteca de Psicopatologia Fundamental). (Trabalho original publicado em 1897).

Lacan, J. (1995). O seminário. Livro 4. A relação de objeto. Rio de Janeiro: Jorge Zahar. (Trabalho original publicado em 1956-1957).

Lacan, J. (2008). Os complexos familiares na formação do indivíduo. Campo Freudiano no Brasil. Rio de Janeiro: Jorge Zahar. (Trabalho original publicado em 1984).

Lacan, J. (1998). O estádio do espelho como formador da função do Eu. In Escritos (pp. 97-103). Rio de Janeiro: Jorge Zahar. (Trabalho original publicado em 1949).

Lachaud, D. (2001). Ciúmes. Rio de Janeiro: Companhia de Freud.

Levy, R. (2009). Os primórdios da construção do ciúme e sua relação com a constituição do laço social. Revista da Associação Psicanalítica de Porto Alegre (Ciúmes), Porto Alegre, n. 37, 22-30.

Moreau, L. (2009). Erotomania. In M. T. Berlinck \& G. E. Berrios, Erotomania (pp. 137148). São Paulo: Escuta. (Biblioteca de Psicopatologia Fundamental). (Trabalho original publicado em 1887).

Moreau, L. (2009). Distinção entre a histeria e a loucura genesíaca. In M. T. Berlinck 
\& G. E. Berrios, Erotomania (pp. 149-152). São Paulo: Escuta. (Biblioteca de Psicopatologia Fundamental). (Trabalho original publicado em 1887).

Quinet, A. (2009). Somos sempre ciumentos? Revista da Associação Psicanalítica de Porto Alegre (Ciúmes), Porto Alegre, n. 37, 131-136.

Sérieux, P. (2009). Delírio erótico. In M. T. Berlinck \& G. E. Berrios, Erotomania (pp. 229234). São Paulo: Escuta. (Biblioteca de Psicopatologia Fundamental). (Trabalho original publicado em 1909).

\section{Resumos}

(From jealousy to erotomania: a clinical case)

This article discusses the topics of jealousy and erotomania on the basis of a clinical case. The concept of jealousy was approached from its manifestation in the early development of the psychic apparatus with possible pathological ramifications arising later. Erotomania was approached through its classical psychiatric reference, rather than through descriptions found in current diagnostic manuals of mental disorders. The author does not go into the matter of diagnosis, but cross-referencing of these two topics showed regressive positions of the subject, with narcissistic and delirious structuring and with a concomitant fragile body image.

Key words: Clinical case, jealousy, erotomania, deliriums

(Sur la jalousie et l'érotomanie: réflexions sur un cas clinique)

Cet article propose une analyse de la jalousie et de l'érotomanie en prenant pour base un cas clinique. La jalousie est comprise à partir de sa manifestation primordiale dans la genèse de la constitution du psychisme et dans ses développements pathologiques. L'érotomanie est approchée par le biais du système de références de la psychiatrie classique et non par celui des manuels de diagnostic actuels. Bien que n'ayant pas une visée diagnostique, l'articulation entre les deux thèmes indique une position subjective régressive, de structuration narcissique et délirante, ainsi qu'une constitution physique fragile.

Mots clés: Cas clinique, jalousie, érotomanie, délire

(Sobre celos y erotomanía: reflexiones acerca de un caso clínico)

Este artículo aborda los temas de los celos y la erotomanía a partir de un caso clínico. Los celos fueron comprendidos a partir de su manifestación primordial en la génesis de la constitución del psiquismo y en sus desdoblamientos patológicos. La erotomanía fue abordada a partir de su referencial psiquiátrico clásico y no de aquel encontrado en los actuales manuales diagnósticos. La articulación de los dos temas 
con el caso, aunque no haya partido de cualquier intención diagnóstica, apuntó para una posición subjetiva, regresiva, de estructuración narcisista, delirante y con frágil conjugación del cuerpo.

Palabras clave: Caso clínico, celos, erotomanía, delirio

(Eifersucht und Erotomanie: Reflexionen zu einem klinischen Fall)

In diesem Beitrag wird Eifersucht und Erotomanie aufgrund eines klinischen Falls besprochen. Die Eifersucht wurde wieder aufgenommen, ausgehend von ihrer primordialen Äußerung in der Genesis der

psychischen Bildung und weiterführend in ihren pathologischen Folgewirkungen. Die Erotomanie wurde ausgehend vom klassischen Referenzrahmen der Psychiatrie untersucht und nicht aufgrund desjenigen der aktuellen diagnostischen Handbücher. Obwohl die Beleuchtung beider Themen nicht irgendeine diagnostische Absicht hatte, wies sie auf eine subjektiv-regressive Position narzisstischer und gestörter Strukturen, sowie eines fragilen Körperbildes hin.

Schlüssewörter: Klinischer Fall, Eifersucht, Erotomanie, Delirium

Citação/Citation: Rios, F. C. (2013, setembro). Sobre ciúmes e erotomania: reflexões acerca de um caso clínico. Revista Latinoamericana de Psicopatologia Fundamental, 16(3), 453-467.

Editor do artigo/Editor: Profa. Dra. Ana Cecília Magtaz (Universidade de São Paulo - USP), São Paulo, SP, Br.

Recebido/Received: 3.2.2013/ 2.3.2013 Aceito/Accepted: 15.5.2013 / 5.15.2013

Copyright: () 2009 Associação Universitária de Pesquisa em Psicopatologia Fundamental/ University Association for Research in Fundamental Psychopathology. Este é um artigo de livre acesso, que permite uso irrestrito, distribuição e reprodução em qualquer meio, desde que o autor e a fonte sejam citados / This is an open-access article, which permits unrestricted use, distribution, and reproduction in any medium, provided the original author and source are credited.

Financiamento/Funding: A autora declara não ter sido financiada ou apoiada / The author has no support or funding to report.

Conflito de interesses/Conflict of interest: A autora declara que não há conflito de interesses / The author declares that has no conflict of interest. 


\section{Fernanda Costa Rios}

Psicóloga pela Pontifícia Universidade Católica de São Paulo - PUC-SP (São Paulo, SP, Br); Psicanalista em formação associada ao Fórum do Campo Lacaniano de São Paulo - FCL-SP (São Paulo, SP, Br); Especialista em Psicopatologia e Sáude Pública pela FSP-USP (São Paulo, SP, $\mathrm{Br}$ ); Membro da Rede Clínica do Laboratório Jacques Lacan do Instituto de Psicologia da Universidade de São Paulo - USP (São Paulo, SP, Br); Membro do Grupo de Psicoses do Instituto de Psiquiatria do Hospital das Clínicas de São Paulo e do Programa de Transtornos do Humor do mesmo Instituto; Psicanalista pesquisadora da Rede de Sintoma e Corporeidade (FCL-SP) no Ambulatório de Dermatologia da Fundação Faculdade de Medicina do ABC - SP (Santo André, SP, Br); Especialista clínica na CRONoS Clinical Consulting Services de Hamilton-New Jersey, EUA.

Rua Caetés, 646 - Perdizes

05016-081 São Paulo, SP, Br.

Fone: (11) 3865-0531

e-mail: ffernandarios@gmail.com 